\title{
Chromosomal aberrations in human hepatocellular carcinomas associated with hepatitis $C$ virus infection detected by comparative genomic hybridization
}

\author{
C Sakakura, ${ }^{1,2}$ A Hagiwara, ${ }^{1}$ H Taniguchi, ${ }^{1}$ T Yamaguchi, ${ }^{1}$ H Yamagishi, ${ }^{1}$ T Takahashi, ${ }^{1}$ K Koyama, ${ }^{3}$ Y Nakamura, ${ }^{3}$ \\ $\mathrm{T} \mathrm{Abe}^{2}$ and $\mathrm{J}$ Inazawa $\mathrm{A}^{2,3,4}$ \\ ${ }^{1}$ First Department of Surgery, ${ }^{2}$ Department of Hygiene, Kyoto Prefectural University of Medicine, Kamigyo-ku, Kawaramachi-dori, Kyoto 602, Japan; ${ }^{3} \mathrm{Human}$ \\ Genome Center, Institute of Medical Science, Tokyo University, 4-6-1 Shirokanedai, Minato-ku, Tokyo 108-8639, Japan; ${ }^{4}$ Department of Molecular Cytogenetics, \\ Medical Research Institute, Tokyo Medical and Dental University, 1-5-45 Yushima, Bunkyo-ku, Tokyo 113-8519, Japan
}

Summary Thirty-five hepatocellular carcinomas (HCCs) associated with hepatitis C virus (HCV) were analysed by comparative genomic hybridization $(\mathrm{CGH})$, to screen for changes in copy-number of DNA sequences. Chromosomal losses were noted in 1p34-36 (37\%), 4q12-21 (48\%), 5q13-21 (35\%), 6q13-16 (23\%), 8p21-23 (28\%), 13q (20\%), 16q (33\%) and 17p13 (37\%). Gains were noted in 1q (46\%), 6p (20\%), 8q21-24 (31\%) and 17q (43\%). High level gains indicative of gene amplifications were found in 7q31 (3\%), 11q13 (3\%), 14q12 (6\%) and $17 q 12$ (3\%); amplification at 14q12 may be characteristic for HCCs. No significant difference in chromosomal aberrations was noted between carcinomas associated with HCV-infection in our study and those reported earlier in HCCs infected with hepatitis B virus (HBV), indicating that both HBV- and HCV-related carcinomas may progress through a similar cascade of molecular events.

Keywords: hepatocellular carcinomas; $\mathrm{CGH}$; chromosomal aberrations

Hepatocellular carcinoma (HCC) is one of the most frequent human cancers worldwide, and it carries a very poor prognosis (Whelan et al, 1993). Although genetic changes underlying the development and progression of HCC are poorly understood, there exist some well-known predisposing factors such as persistent hepatitis due to viral infection and exposure to mycotoxins (Rensburg et al, 1985; Nalpas et al, 1991; Tanaka et al, 1991). In fact, most of HCC are associated with a background of chronic liver disease (chronic viral hepatitis or cirrhosis). Both activation of cellular oncogenes and inactivation of tumour suppressor genes have been implicated in previous studies (Rogler et al, 1992; Tabor et al, 1994; Di Bisceglie et al, 1997; Nishida et al, 1997).

Cellular proto-oncogenes may be activated through insertion of a viral genome, a process similar to integration of retrovirus; in a few cases, mutagenesis resulting from integration of hepatitis B virus (HBV) into cellular genes has appeared to be linked to hepatocarcinogenesis (Wang et al, 1990). However, since most HCCs accompanied by infection with HBV contain viral DNA integrated in the genome, this mechanism, as well as oncogene activation, has been proposed as a general contributor to the development of hepatocellular carcinoma (Simon and Carr, 1995). By contrast, to our knowledge hepatitis $\mathrm{C}$ virus (HCV) is never integrated into the genomes of hepatocytes (Fong et al, 1991; Kasai et al, 1996; Di Bisceglie et al, 1997). The carcinogenic mechanisms of both viruses are still under intensive investigations.

Received 27 October 1998

Accepted 16 February 1999

Correspondence to: J Inazawa, Department of Molecular Cytogenetics, Medical Research Institute, Tokyo Medical and Dental University, Yushima 1-5-45, Bunkyo-ku, Tokyo 113-8519, Japan
Among the tumour suppressors most frequently inactivated in HCCs is the p53 gene, mutated in 25-60\% of these tumours (Oda et al, 1992; Fujimoto et al, 1994). Losses of heterozygosity (LOH) at chromosomes 1p, 4q, 5q, 8p, 11p, 13q, 16q, 17p and/or 22q are common in HCC (Tsuda et al, 1990; Zhang et al, 1990; Fujimori et al, 1991; Simon et al, 1991). Classical cytogenetic studies have detected losses of the same chromosome arms in HCCs (Fourel et al, 1994). Therefore, some putative tumour suppressor genes at these loci may be involved in the development and progression of HCC.

Comparative genomic hybridization $(\mathrm{CGH})$ is a molecular cytogenetic method that makes it possible to survey the entire genome for gains and losses of DNA sequences (Kallioniemi et al, 1992, 1994). The utility of CGH is based on the concept that regions with increased copy number reveal chromosomal sites that may contain dominant oncogenes, whereas regions with decreased copy number may be loci of putative tumour suppressor genes (Kallioniemi et al, 1992, 1994). CGH reliably screens the entire human genome, and therefore allows detection of any chromosomal sites that are likely to contain genes with an important role in tumour development (Ariyama et al, 1998; Sakakura et al, 1999).

In the study reported here, CGH analysis was performed in 35 cases of $\mathrm{HCC}$ with $\mathrm{HCV}$ infection (hereafter, HCV-HCC) in order to identify those regions that contain potential oncogenes or tumour suppressor genes responsible for hepatocellular carcinogenesis.

\section{MATERIALS AND METHODS}

\section{Primary tumour specimens}

The material consisted of 35 primary human hepatocellular carcinomas with $\mathrm{HCV}$ infection. The clinical stage distribution of these 
Table 1 DNA copy number changes in each of 35 hepatocellular carcinomas

\begin{tabular}{|c|c|c|c|}
\hline Sample no. & Gain & Loss & Histology, stage \\
\hline 1 & - & $12 q, X$ & Ed1, T2NOM0 Stage 2 \\
\hline 2 & $1 q, 7 q 31,12 q, 14 q 12$ & $1 \mathrm{p}$ & Ed3, T3N0M0 Stage 3 \\
\hline 3 & $14 q 12,8 q, 9 q, 16 p, 19 p, 20$ & $1 p, 4 q, 5 q, 8 p, 10,11 q, 13 q$ & Ed3, T1NOM0 Stage 1 \\
\hline 4 & $8 q$ & $1 p 31-36,4 q, 6 q, 8 p$ & Ed2, T2NXM0 Stage 2 \\
\hline 5 & $1 q, 3,6,17 q$ & $4,11,12 p, 13 q, 14 q, 15 q, 18 p$ & Ed3, T3N0M0 Stage 3 \\
\hline 6 & $1 q, 5 p, 8 q$ & $4 q, 5,8 p, 14 q, 17 p, 19$ & Ed2, T2NOMO Stage 2 \\
\hline 7 & - & - & Ed2, T3N0M0 Stage 3 \\
\hline 8 & $1 q, 7,15 q, 16 p$ & $1 p, 4 q, 5 q, 13 q, 16 q$ & Ed2, T4N0M0 Stage 4a \\
\hline 9 & $1 q, 8 q, 17 q, 20$ & $2,3,4,5 q, 6 q 14-26,11$ & Ed2, T2N0M0 Stage 2 \\
\hline 10 & $1 q, 8 q, 10,14 q$ & $1 p, 7 q, 10 q, 16,17,18 q, 19,20,21 q$ & Ed2, T1N0M0 Stage 1 \\
\hline 11 & $3,10 q, 12,17 q, 20$ & $1 p 34-36,3 p 12-13,4 q, 7,16,17 p 13$ & Ed2, T4NOM0 Stage 4a \\
\hline 12 & $1 q, 3,4 p, 5 q, 6,16,17 q$ & $10,15 q, 21 q, X p, X q 12-21$ & Ed4, T3N0M0 Stage 3 \\
\hline 13 & $3,17 q, X q$ & $5 p, 5 q 11-32,15 q, 18$ & Ed2, T1N0M0 Stage 1 \\
\hline 14 & $7,8 q, 17 q, 19 q, 20,22 q$ & $8 p, 12 p$ & Ed3, T4NXM0 Stage $4 a$ \\
\hline 15 & $1 q, 6 p, 7 p 14-22,14 q, 15 q, 17 q, 21 q$ & $3 p 22-26,4 q, 6 q, 7 p, 12 q$ & Ed2, T2NOM0 Stage 2 \\
\hline 16 & $1 q, 1 q, 8 q, 15 q$ & $9 q, 12 q 24,16,17,19,20,21 q$ & Ed2, T2NOMO Stage 2 \\
\hline 17 & $15 q$ & $1 \mathrm{p}$ & Ed2, T3N0M0 Stage 3 \\
\hline 18 & $1 q, 2,8 q, 11,12,14 q, 17 q, 18,19$ & $1 p, 4 q$ & Ed3, T3NOMO Stage 3 \\
\hline 19 & $1 q, 3,4 p, 11 p, 17,19 q, 21 q$ & $1 p, 4 q, 6 q, 9 q 22-24,16,17 p 13,18,19$ & Ed4, T3N0M0 Stage 3 \\
\hline 20 & - & $17 p$ & Ed2, T2NOMO Stage 2 \\
\hline 21 & $1 q, 2,3,11 q 13,17 q, X$ & $4 q 12-31,9 q 31-34,17 p, 19,21 q, 22 q$ & Ed1, T3N0M0 Stage 3 \\
\hline 22 & $2,4,11 p, 13 q, 15 q, 19$ & $5 q 14-23,6 q$ & Ed2, T3NOMO Stage 3 \\
\hline 23 & $6 p, 17 q$ & $6 q, 17 p, 8 p 21-23$ & Ed2, T3NOM0 Stage 3 \\
\hline 24 & $1 q, 8 q, 10 p, 17 q, 20,21 q$ & $1 p, 2,4,5,8 q, 9 p 22-24,13 q, 16 q, 17 p, X$ & Ed3, T2NOMO Stage 2 \\
\hline 25 & $2,6,16 p, X$ & $1 p, 4 q, 13 q, 16 q, 18 q$ & Ed2, T3N0M0 Stage 3 \\
\hline 26 & $1 q, 2 p, 6 p, 8 q, 17,20, x$ & $1 p, 5 q, 6 q, 16,18,20$ & Ed2, T4NOM0 Stage 4a \\
\hline 27 & $17 q 12$ & $17 p, 19,22 q$ & Ed4, T4NOM0 Stage 4a \\
\hline 28 & - & - & Ed2, T2NOM0 Stage 2 \\
\hline 29 & - & - & Ed2, T3N0M0 Stage 3 \\
\hline 30 & $8 q, 18,19 q, X$ & $1 q 22-32,2 q, 4,6 q, 13 q, 17,19$ & Ed2, T4NOM0 Stage $4 a$ \\
\hline 31 & $1 q, 4 p$ & $4 q, 5 q, 8 p, 16,19,22 q$ & Ed3, T2N0M0 Stage 2 \\
\hline 32 & $2 p, 17,8 q 21-24$ & $5 q, 6,8 p, 17 p, 21 q$ & Ed2, T3N0M0 Stage 3 \\
\hline 33 & $11 p, 16 p, 17 q, 19 p, 20$ & $4,8 p, 9 p, 16 q, 19,21 q$ & Ed3, T4NOMO Stage $4 a$ \\
\hline 34 & $1 q, 11 p, 15 q, 21 q$ & $5 q, 8 p, 9,16 q, 17 p 13,19$ & Ed2, T3N0M0 Stage 3 \\
\hline 35 & $6 p, 9 q, 11,12 q 14-22$ & $1 p, 4,5 q, 8 p 21-23,12 p, 13 q, 16 q, 17 p$ & Ed3, T2NOMO Stage 2 \\
\hline
\end{tabular}

*The regions of high level gain are written in bold. TNM classification of UICC was used for staging system. Edmondson classification was used for histological classification.

cases was as follows: stage 1, three cases; stage 2, 11 cases; stage 3, 14 cases; stage 4, seven cases. High molecular weight tumour DNA was isolated from homogenized tumour specimens using standard protocols. Normal human male DNA was also isolated from the peripheral blood of a male volunteer as using a reference DNA for CGH.

\section{CGH and digital image analysis}

CGH was performed using directly fluorochrome-conjugated DNA as described elsewhere (Ariyama et al, 1998; Sakakura et al, 1999). Three single-colour images (DAPI, Spectrum green and Texas red fluorescence) were collected from each metaphase spread using an epifluorescence microscope (Nikon, Tokyo, Japan), a cooled charge-coupled device (CCD) camera (Hamamatsu Photonics, Hamamatsu, Japan), and analysed using a digital image analysis system, The Power Gene, Mac Probe (PSI, Perceptive Scientific Instrument). Chromosomal regions where the mean ratio fell below 0.8 were therefore considered to reflect losses of DNA (underrepresentation), whereas regions where the mean ratio exceeded 1.2 were considered gained (overrepresentation) in the tumour genome. Overrepresentations were considered to be high-level amplifications when the fluorescence ratio exceeded 1.5 (Sakakura et al, 1999). Heterochromatic regions near the centromeres and the entire Y chromosome were excluded from analysis.

\section{RESULTS}

An overview of genetic changes in $35 \mathrm{HCCs}$ is shown in Figure 1 and listed in Table 1. Thirty-two tumours (92\%) showed DNA sequence copy number changes, which was significantly higher than previous cytogenetic studies had indicated (Lowichik et al, 1996). This reflects the power of CGH in revealing aberrations across the genome in uncultured cells. Three tumours had no copy number changes. None of six normal liver tissues showed any gains or losses of DNA sequence copy number (data not shown). Losses in HCC predominated over gains with a ratio of 1:1.2. On average, there were 7.6 (range $0-12$ ) aberrations per primary tumour: 3.4 gains (range $0-6$ ) and 4.2 losses (range $0-7$ ).

The most common copy number changes were losses at 1p34-36 (13/35; 37\%), 4q12-21 (17/35; 48\%), 5q13-21 (12/35; $35 \%), 6 q 13-16(8 / 35 ; 23 \%), 8 p 21-23(10 / 35 ; 28 \%), 13 q(7 / 35$; $20 \%), 16 \mathrm{q}(12 / 35 ; 33 \%)$ and $17 \mathrm{p} 13(13 / 35 ; 37 \%)$. Gains were seen in 1q $(16 / 35 ; 46 \%), 6 p(7 / 35 ; 20 \%), 8 q 21-24(11 / 35 ; 31 \%)$ and $17 \mathrm{q}(15 / 35 ; 43 \%)$. Minimal overlapping regions of common DNA copy number changes in these HCCs, and their relationship to known locations of oncogenes, tumour suppressor genes, or 

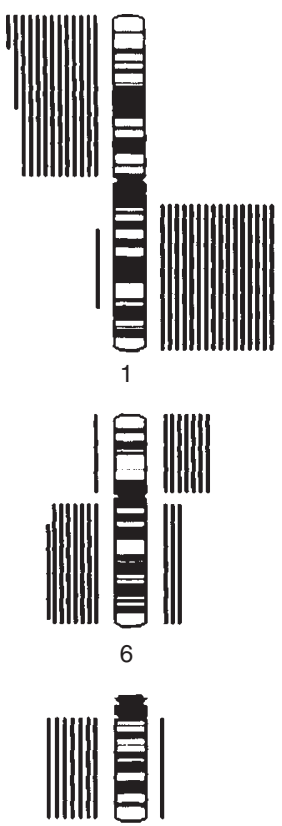

13

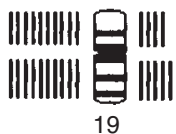

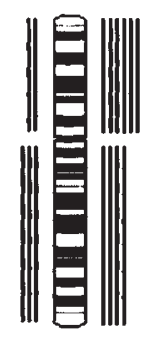

2

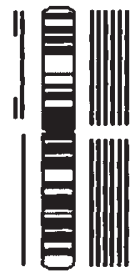

3

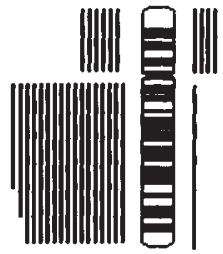

4

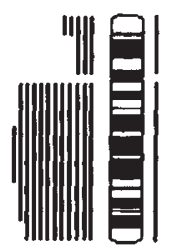

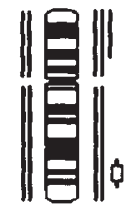

7

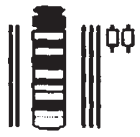

14

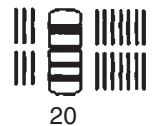

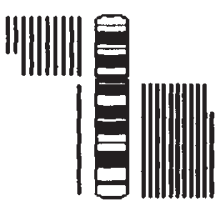

8

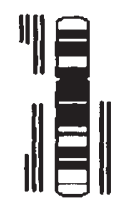

9
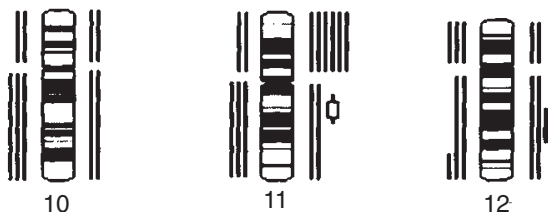

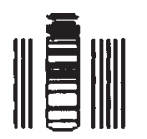

15

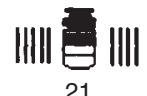

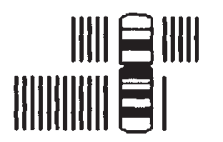

16

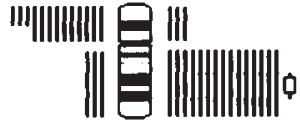

17

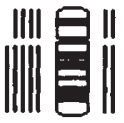

18

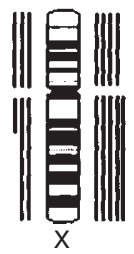

Figure 1 Schematic view of DNA copy number changes in 35 human hepatocellular carcinomas, with CGH data plotted in ideogram form. The 22 autosomal chromosomes and the $\mathrm{X}$ chromosome are represented by ideograms showing G-banding patterns, oriented with $p$-arms at the top. Each region of decrease in DNA is represented as a thin solid line to the left of and parallel to the chromosomal region where it occurs, as judged by computerized green-to-red profiles (see Materials and Methods). Each copy number increase is likewise represented as a thin solid line, to the right of the region where it occurs. Regions of frequent copy number change have multiple parallel lines beside them, and gene amplifications are indicated by open rectangles. The data are summarized in Tables 1 and 2

adhesion molecule genes are listed in Table 2. High level gains indicative of amplified genes were found in $7 \mathrm{q} 31(1 / 35 ; 3 \%)$, $11 \mathrm{q} 13(1 / 35 ; 3 \%), 14 \mathrm{q} 12(2 / 35 ; 6 \%)$ and $17 \mathrm{q} 12(1 / 35 ; 3 \%)$.

Figure $2 \mathrm{~A}$ shows the typical two-colour image among our panel of CGH. The DAPI-stained image of the same metaphase from which the chromosomes were identified is shown in Figure 2B. Its copy number profile is shown in Figure 2C. DNA gains are evident on chromosomes 1q, 5p and 8q. Losses on chromosomes 4, 5q, 8p, $14 q 17 p$ and 19 are also readily apparent.

\section{DISCUSSION}

Screening for HBV prior to blood transfusion has decreased the incidence of HCC with HBV infection in Japan, and more than $80 \%$ of HCC in Japan is now associated with HCV infection (Tanaka et al, 1991; The Liver Cancer Study Group in Japan, 1994; Takano et al, 1995). The role of HCV-infection in the aetiology of HCC and cirrhosis now seems to be more important than chronic hepatitis B infection. Although HBV is randomly integrated into the genome of hepatocytes in more than $90 \%$ of HCC with HBV infection (HBV-HCC) (Tokino et al, 1987; Tabor et al, 1994), HCV does not integrate into the genome as far as we know (Fong et al, 1991; Di Biscegli et al, 1997). The mechanism by which HCV contributes to development of HCC is unclear.
Table 2 Minimal overlapping regions of common DNA copy number changes in hepatocellular carcinoma

\begin{tabular}{|c|c|c|c|}
\hline $\begin{array}{l}\text { DNA } \\
\text { copy number }\end{array}$ & Locus & Frequency & Putative target genes \\
\hline \multirow[t]{4}{*}{ Increase } & $1 q$ & $46 \%(16 / 35)$ & PTPRC, ARG \\
\hline & $6 p$ & $20 \%(7 / 35)$ & PIM1 \\
\hline & $8 q 21-24$ & $31 \%(11 / 35)$ & $M Y C$ \\
\hline & $17 q$ & $43 \%(15 / 35)$ & $E R B B 2$ \\
\hline \multicolumn{4}{|c|}{ High level gain (amplification) } \\
\hline & $7 q 31$ & $3 \%(1 / 35)$ & MET \\
\hline & $11 q 13$ & $3 \%(1 / 35)$ & HST1/INT2 \\
\hline & $14 q 12$ & $6 \%(2 / 35)$ & \\
\hline & $17 q 12$ & $3 \%(1 / 35)$ & $E R B B 2$ \\
\hline \multirow[t]{8}{*}{ Decrease } & 1p34-36 & $37 \%(13 / 35)$ & TP73 \\
\hline & $4 q 12-21$ & $48 \%(17 / 35)$ & \\
\hline & $5 q 13-21$ & $35 \%(12 / 35)$ & $A P C$ \\
\hline & $6 q 13-16$ & $23 \%(8 / 35)$ & \\
\hline & $8 p 21-23$ & $28 \%(10 / 35)$ & \\
\hline & $13 q$ & $20 \%(7 / 35)$ & $R B$ \\
\hline & $16 q$ & $33 \%(12 / 35)$ & E-Cadherin (CDH1) \\
\hline & $17 q 13$ & $37 \%(13 / 35)$ & TP53 \\
\hline
\end{tabular}

However, as patients with $\mathrm{HCV}$ infection tend to be older and show more severe liver cirrhosis than patients with HBV-HCC, not only the background but also the mechanism involved in initiation of carcinogenesis may be different for the two viruses. 


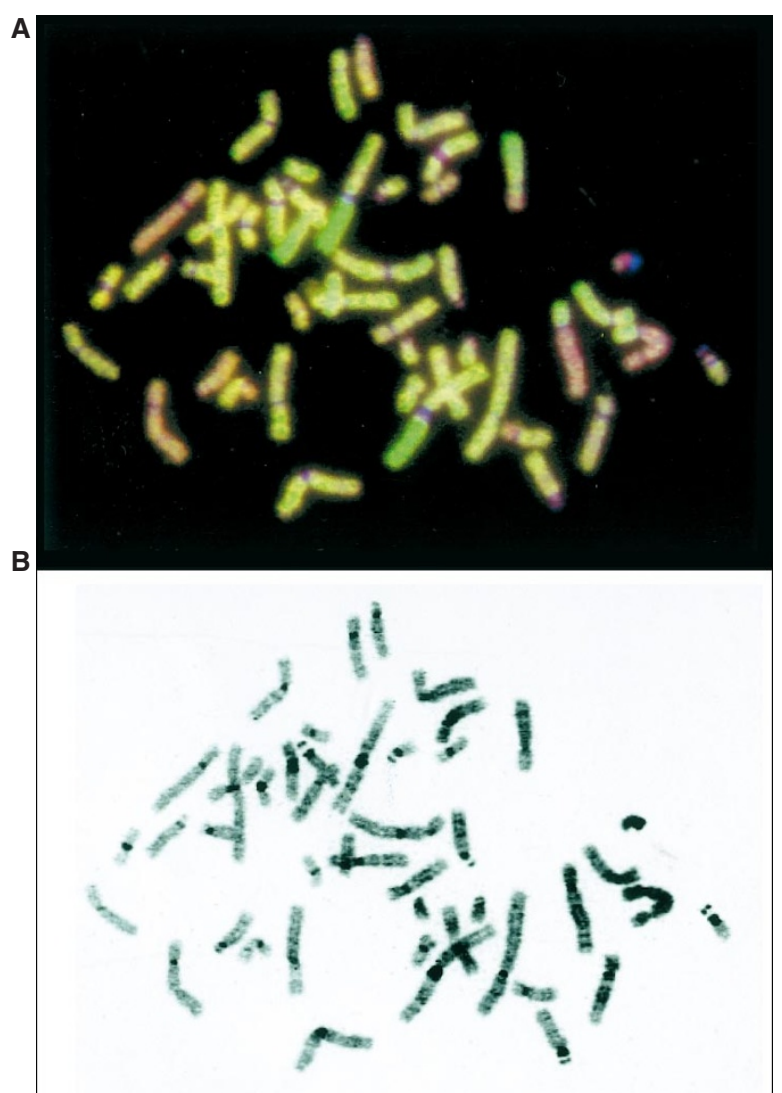

Figure 2 (A) Typical two-colour image of CGH in hepatocellular carcinoma. Differentially labelled tumour (green) and normal (red) DNAs were hybridized onto a normal human metaphase spread $(46, X Y)$. Chromosomal regions that are overrepresented in the tumour appear green, regions that are underrepresented appear red and unrelated regions appear yellow. Chromosomes showing copy number changes are numbered at their q ends; DNA gains are evident on chromosomes $1 \mathrm{q}, 5 \mathrm{p}$ and $8 \mathrm{q}$. Losses on chromosomes $4,5 \mathrm{q}, 8 \mathrm{p}$, $14 q$ and $17 p$ are also readily apparent. (B) DAPI-stained image of the same metaphase cell shown in panel A. DAPI banding patterns were used for chromosome identification.

Our CGH analysis of $35 \mathrm{HCV}-\mathrm{HCCs}$ showed frequent imbalances on chromosomes 1, 4q, 5q, 6, 8, 16q and 17. These data are concordant with the results recently reported for HBV-HCCs (Marchio et al, 1997); a similar cohort of oncogenes and suppressor genes at these loci may be involved in the development and progression of both HBV- and HCV-related HCC. Our CGH results also agree with those of investigators who found no correlation between $\mathrm{LOH}$ in specific chromosomal regions and chronic infections with hepatitis B or C (Konishi et al, 1993; Nagai et al, 1997).

$\mathrm{LOH}$ analyses have revealed that allelic loss of $4 \mathrm{q}$ is a frequent change in early-stage HCCs (Fujimoto et al, 1991; Nagai et al, 1996), and this chromosomal region is thought to harbour one or more tumour suppressor genes (Buetow et al, 1989; Yeh et al, 1996). To our knowledge, underrepresentation of this locus, as revealed by $\mathrm{CGH}$, has never been reported in other types of cancers, so HCC-specific tumour suppressor genes may exist there. Another group of investigators reports that loss of 4q21-22 region occurred preferentially in well-differentiated HCC and they considered this a secondary event that increased the aggressiveness of established cancer (Kuroki et al, 1995). It has also been reported that loss of $4 \mathrm{q}$ is related to increased serum AFP (alpha-fetoprotein) levels (Yeh et al, 1996). In our CGH analysis of HCCs, the most commonly recurrent loss (4q) was observed in $45 \%$ of tumour specimens, the smallest region of overlap being $4 q 12-21$. This result supported the view that chromosome $4 \mathrm{q}$, particularly $4 \mathrm{q} 12-21$, harbours tumour suppressor activity that is lost during tumorigenesis in HCV-HCC.

We have explored possible correlations between clinicopathological characteristics and copy number changes in the tumours of our panel. The first objective of the statistical analysis was to examine relationship of total copy number changes with cancer stage. Information obtained from the univariate analysis (log-rank test) was applied to total copy number changes with cancer stage using the Cox model of proportional hazards, but we have found no relation between two factors. In the same way, we tried to analyse the relationship between copy number changes on specific chromosomes and tumour stage, but it could not be evaluated statistically because too few early-stage tumours (three cases) were among the total. Changes on $1 \mathrm{p}, 1 \mathrm{q}$ and $4 \mathrm{q}$ were detected in the HCCs classified as stage $\mathrm{T} 1(<2 \mathrm{~cm}$ in diameter) with almost same frequency as more advanced HCCs.

The recurrently underrepresented sites observed in this CGH study, i.e. 1 p, $5 p, 16 q$ and $17 p$, have also been reported to be common regions of allelic loss in HCC. Each of these segments is a known or suspected site of tumour suppressor genes, e.g. p53 at $17 \mathrm{p} 13, A P C$ at $5 \mathrm{q} 21, R B$ at $13 \mathrm{q} 14, C D H 1$ at $16 \mathrm{q} 21-24$. Frequent genetic alterations in the distal region of chromosome $1 \mathrm{p}$ in HCCs suggest loss of this region is critical for initial hepatocarcinogenesis (Yeh et al, 1994). Recently p73, whose function is related to $\mathrm{p} 53$, was isolated from 1p36 (Kaghad et al, 1997). Unidentified suppressor genes associated with HCC appear to present on chromosome $8 \mathrm{p}$ (Emi et al, 1993; Fujiwara et al, 1994). The underrepresentation of $17 \mathrm{p}(45 \%)$ in our study is explained by loss of the p53 gene (17p13.1), a frequent feature of HCC (Fujimoto et al, 1994).

Over-representation of chromosome arm 1q was the most frequent feature in our series of tumours that shows copy-number increases; 16 of them exhibited gain involving 1q. Moreover, increased copy number at $1 \mathrm{q}$ has also been reported in a variety of other tumours including breast, gastric and neuroblastoma, all related to poor prognosis and sometimes to metastases (Borg et al, 1992; Tahara, 1995). Chromosome 1q contains the Abelsonrelated oncogene $(A R G$; Kruh et al, 1990) and the protein tyrosine phosphatase receptor type c polypeptide gene (PTPRC; Schaapveld et al, 1995), both of which are associated with cell growth and proliferation.

Overrepresentations of $17 \mathrm{q}$ and $8 \mathrm{q}$, the second and third most common gains of DNA observed in this series, included amplification of $17 \mathrm{q} 12$ in one tumour. A potentially relevant gene on 17q12, $E R B B 2$, encodes an EGF-like growth factor receptor (Kameda et al, 1990); another, whose product may contribute to control of cell proliferation and malignant transformation, is $M Y C$; a gene that is over-expressed in most HCCs (Moroy et al, 1986). Gains at $6 \mathrm{p}(20 \%$ in our study) have not been previously described in HCC, although tumour-specific copy number increases at $6 \mathrm{p}$ have been reported in retinoblastomas and osteosarcomas (Cano et al, 1994; Forus et al, 1995), where PIM1 may be one of the target genes.

$\mathrm{CGH}$ is particularly powerful in revealing discrete amplified loci. In our analysis, we detected four distinct amplification sites; $7 \mathrm{q} 31,11 \mathrm{q} 13,14 \mathrm{q} 12$ and 17q12. Putative target genes on $7 \mathrm{q} 31$, $11 \mathrm{q} 13$ and $17 \mathrm{q} 12$ are $M E T, H S T / I N T 2$ and ERBB2, respectively, but amplification on $14 \mathrm{q} 12$ has never been reported in any other type of cancer. Therefore a novel gene whose overexpression is specific for HCC may exist there; amplification of this locus has 

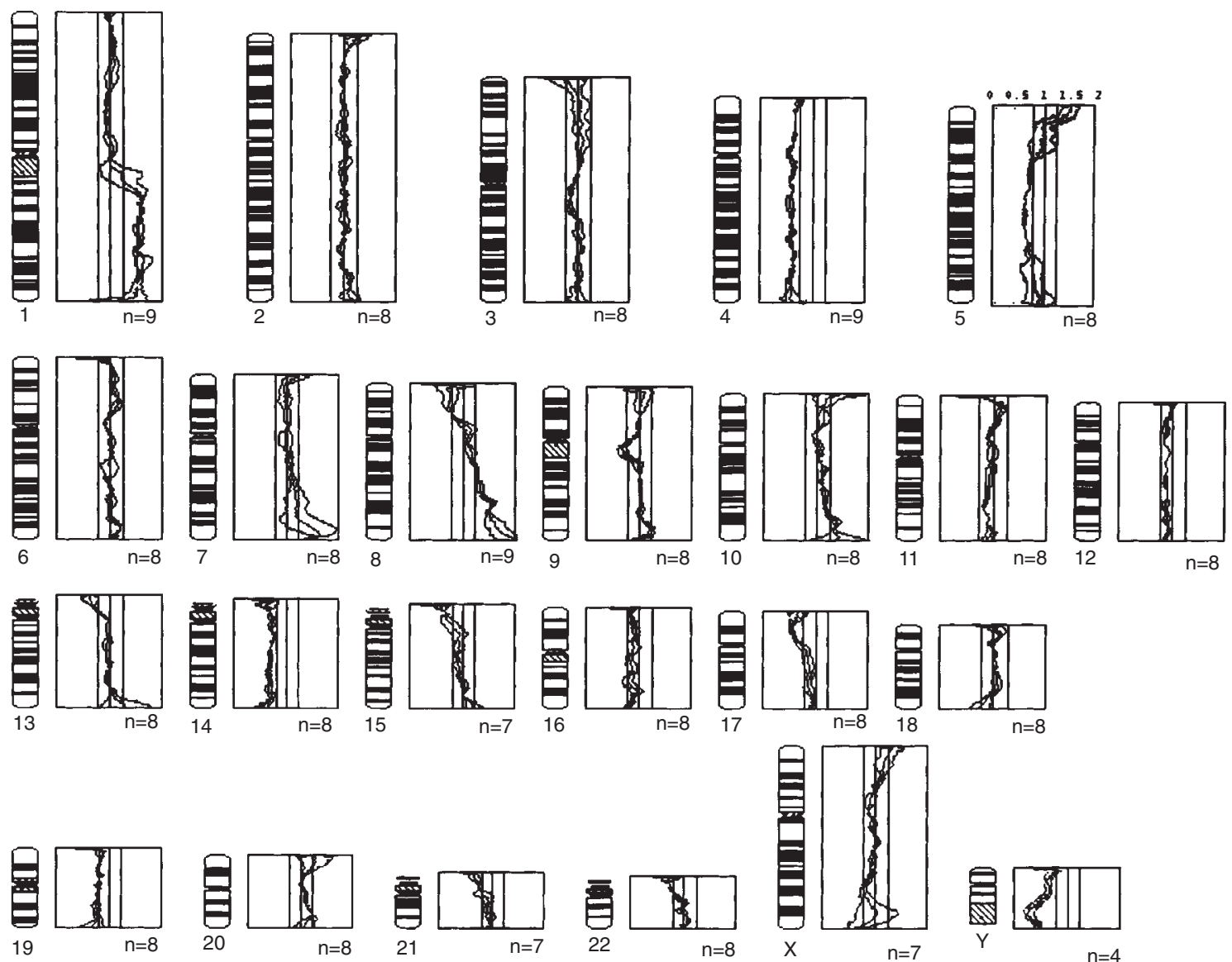

Figure 2C Computer-generated mean and standard deviation fluorescence ratio profiles for several metaphases from the hepatocellular carcinoma (Sample No 6). The central horizontal dashed line represents a green-to-red fluorescence ratio of 1 (no copy number change)

also been detected in HBV-HCC, along with amplifications of 11q13, 12p11 and 19q13 (Marchio et al, 1997). Amplifications we observed at $7 \mathrm{q} 31,11 \mathrm{q} 13$ and $17 \mathrm{q} 12$ have also been reported in other types of cancers (Tahara et al, 1994; Knuutila et al, 1998).

In summary, the recurrent copy number decreases we identified by $\mathrm{CGH}$ analysis support previous data on allelic loss in HCCs, and further implicate those sites as locations of tumour suppressor genes. Our study reveals that the pattern of chromosomal aberrations in $\mathrm{HCC}$ with $\mathrm{HCV}$ infection, although highly complex and involving virtually every chromosome, is clearly non-random and similar to CGH pattern of HCCs with HBV infection. In addition, many of the overrepresented chromosome segments observed in HCC are sites of known oncogene/growth-regulatory genes already implicated in tumorigenesis. Other overrepresented regions could be sites of novel amplified DNA sequences which may provide growth advantages in these aggressive neoplasms.

\section{ACKNOWLEDGEMENTS}

This work was supported by grants-in-aid from the Ministry of Health and Welfare; the Ministry of Education, Science, Sports and Culture; the Organization for Pharmaceutical Safety and Research, Japan; a grant from Cell Fate Modulation Research Unit; and Research Grant of the Princess Takamatsu Cancer Research Fund.

\section{REFERENCES}

Ariyama Y, Fukuda Y, Okuno Y, Seto M, Date K, Abe T, Nakamura Y and Inazawa J (1998) Amplification on double-minute chromosomes and partial-tandem duplication of the MLL gene in leukemic cells of a patient with acute myelogenous leukemia. Genes Chromosomes Cancer 23: 267-272

Borg A, Zhang QX, Olsson H and Wenngren E (1992) Chromosome 1 alterations in breast cancer: allelic loss on $1 \mathrm{p}$ and $1 \mathrm{q}$ is related to lymphogenic metastases and poor prognosis. Genes Chromosomes Cancer 5: 311-320

Buetow KH, Murray JC, Israel JL, London WT, Smith M, Kew M, Blanquet V, Brechot C, Redeker A and Govindarajah S (1989) Loss of heterozygosity suggests tumor suppressor gene responsible for primary hepatocellular carcinoma. Proc Natl Acad Sci USA 86: 8852-8856

Cano J, Oliveros O and Yunis E (1994) Phenotype of variants malignancy, additional copies of 6p in retinoblastoma. Cancer Genet Cytogenet 76: 112-115

Di Biscegli AM (1997) Hepatitis C and hepatocellular carcinoma. Hepatology 26: 34S-38S

Emi M, Fujiwara Y, Ohata H, Tsuda H, Hirohashi S, Koike M, Miyaki M, Monden $\mathrm{M}$ and Nakamura Y (1993) Allelic loss at chromosome band 8p21.3-p22 is associated with progression of hepatocellular carcinoma. Genes Chromosomes Cancer 7: 152-157

Fong TL, Shindo M, Feinstone SM, Hoofnagle JH and Di Bisceglie AM (1991) Detection of replicative intermediates of hepatitis $\mathrm{C}$ viral RNA in liver and serum of patients with chronic hepatitis C. J Clin Invest 88: 1058-1060

Forus A, Weghuis DO, Smeets D, Fodstad O, Myklebost O and Geurts Van Kessel A (1995) Comparative genomic hybridization analysis of human sarcomas: II. Identification of novel amplicons at $6 \mathrm{p}$ and $17 \mathrm{p}$ in osteosarcomas. Genes Chromosomes Cancer 14: 15-21

Fourel G (1994) Genetic and epigenetic alterations of gene expression in the course of hepatocarcinogenesis. In: Liver Gene Expression, Tronche F and Moshe Y (eds), pp. 298-343. R.G. Landes: Austin, TX 
Fujimori M, Tokino T, Hino O, Kitagawa T, Imamura T, Okamoto E, Mitsunobu M, Ishikawa T, Nakagawa H, Hayada H, Yagura M, Matsubara K and Nakamura Y (1991) Allotype study of primary hepatocellular carcinoma. Cancer Res 51: 89-93

Fujimoto Y, Hampton LL, Wirth PJ, Wang NJ, Xie JP and Thorgeirsson SS (1994) Alteration of tumor suppressor genes and allelic losses in human hepatocellular carcinomas in China. Cancer Res 54: 281-285

Fujiwara Y, Ohata H, Emi M, Okui K, Koyama K, Tsuchiya E, Nakajima T, Monden M, Mori T, Kurimasa A, Oshimura M and Nakamura Y (1994) A 3-Mb physical map of the chromosome region 8p21.3-p22, including a 600-kb region commonly deleted in human hepatocellular carcinoma, colorectal cancer, and non-small cell lung cancer. Genes Chromosomes Cancer 10: 7-14

Kaghad M, Bonnet H, Yang A, Creancier L, Biscan JC, Valent A, Minty A, Chalon P, Lelias JM, Dumont X, Ferrara P, McKeon, F and Caput D (1997) Monoallelically expressed gene related to $\mathrm{p} 53$ at $1 \mathrm{p} 36$, a region frequently deleted in neuroblastoma and other human cancers. Cell 90: 809-819

Kallioniemi A, Kallioniemi OP, Sudar D, Rutovitz D, Gray JW, Waldman F and Pinkel D (1992) Comparative genomic hybridization for molecular cytogenetic analysis of solid tumors. Science 258: 818-820

Kallioniemi A, Kallioniemi O-P, Piper J, Tanner M, Stokke T, Chen L, Smith HS, Pinkel D, Gray JW and Waldman FM (1994) Detection and mapping of amplified DNA sequences in breast cancer by comparative genomic hybridization. Proc Natl Acad Sci USA 91: 2156-2160

Kameda T, Yasui W, Yoshida K, Tsujino T, Nakayama H, Ito M, Ito H and Tahara E (1990) Expression of ERBB2 in human gastric carcinomas; relationship between p185ERBB2 and the gene amplification. Cancer Res 15: 8002-8009

Kasai Y, Takeda S and Takagi H (1996) Pathogenesis of hepatocellular carcinoma: a review from the viewpoint of molecular analysis. Semin Surg Oncol 12: $155-159$

Knuutila S, Bjorkqvist AM, Autio K, Tarkkanen M, Wolf M, Monni O, Szymanska J, Larramendy ML, Tapper J, Pere H, El-Rifai W, Hemmer S, Wasenius VM, Vidgren V and Zhu Y (1998) DNA copy number amplifications in human neoplasms: review of comparative genomic hybridization studies. Am J Pathol 152: $1107-1123$

Kruh GD, Perego R, Miki T and Aaronson SA (1990) The complete coding sequence of arg defines the Abelson subfamily of cytoplasmic tyrosine kinases. Proc Natl Acad Sci USA 87: 5802-5806

Kuroki T, Fujiwara Y, Tsuchiya E, Nakamori S, Imaoka S, Kanematsu T and Nakamura Y (1995) Accumulation of genetic changes during development of and progression of hepatocellular carcinoma: Loss of heterozygosity on chromosome arm 1p occurs at early stage of hepatocarcinogenesis. Genes Chromosomes Cancer 13: 163-167

Lowichik A, Schneider NR, Tonk V, Ansari MQ and Timmons CF (1996) Report of a complex karyotype in recurrent metastatic fibrolamellar hepatocellular carcinoma and a review of hepatocellular carcinoma cytogenetics. Cancer Genet Cytogenet 88: 170-174

Marchio A, Meddeb M, Pineau P, Danglot G, Tiollais P, Bernheim A and Dejean A (1997) Recurrent chromosomal abnormalities in hepatocellular carcinoma detected by comparative genomic hybridization. Genes Chromosomes Cancer 18: $59-65$

Moroy T, Marchio A, Etiemble J, Trepo C, Tiollais P and Buendia MA (1986) Rearrangement and enhanced expression of c-myc in hepatocellular carcinoma of hepatitis virus infected woodchucks. Nature 324: 276-279

Nagai H, Pineau P, Tiollais P, Buendia MA and Dejean A (1997) Comprehensive allelotyping of human hepatocellular carcinoma. Oncogene 14: 2927-2933

Nalpas B, Driss F, Pol S, Hamelin B, Housset C, Brechot C and Berthelot P (1991) Association between $\mathrm{HCV}$ and $\mathrm{HBV}$ infection in hepatocellular carcinoma and alcoholic liver disease. J Hepatol 12: 70-74
Nishida N, Fukuda Y, Ishizaki K and Nakao K (1997) Alteration of cell cycle-related genes in hepatocarcinogenesis. Histol Histopathol 12: 1019-1025

Oda T, Tsuda H, Scarpa A, Sakamoto M and Hirahashi S (1992) P53 gene mutation spectrum in hepatocellular carcinoma. Cancer Res 52: 6358-6364

Rogler CE and Chisari FV (1992) Cellular and molecular mechanisms of hepatocarcinogenesis. Semin Liver Dis 12: 265-278

Sakakura C, Mori T, Sakabe T, Ariyama Y, Shinomiya T, Date K, Hagiwara A, Yamaguchi T, Takahashi T, Nakamura Y, Abe T and Inazawa J (1999) Gains, losses, and amplifications of genomic materials in primary gastric cancers analyzed by comparative genomic hybridization. Genes Chromosomes Cancer 24: 299-305

Schaapveld RQ, Van Den Maagdenberg AM, Schepens JT, Weghuis DO, Geurts Van Kessel A, Wieringa B and Hendriks WJ (1995) The mouse gene Ptprf encoding the leukocyte common antigen-related molecule LAR: cloning, characterization, and chromosomal localization. Genomics 27: 124-130

Simon D, Knowles BB and Weith A (1991) Abnormalities of chromosome 1 and loss of heterozygosity of $1 \mathrm{p}$ in primary hepatomas. Oncogene 6: 765-770

Simon D and Carr BI (1995) Integration of hepatitis B virus and alteration of the $1 \mathrm{p} 36$ region found in cancerous tissue of primary hepatocellular carcinoma with viral replication evidenced only in noncancerous, cirrhotic tissue. Hepatology 22: 1393-1398

Tabor E (1994) Tumor suppressor genes, growth factor genes, and oncogenes in hepatitis B virus-associated hepatocellular carcinoma. J Med Virol 42: 357-365

Tahara E (1995) Molecular biology of gastric cancer. World J Surg 19: 484-488

Takano S, Yokosuka O, Imazeki F, Tagawa M and Omata M (1995) Incidence of hepatocellular carcinoma in chronic hepatitis B and $\mathrm{C}$ : a prospective study of 251 patients. Hepatology 21: $650-655$

Tanaka K, Hirohata T, Koga S, Sugimachi K, Kanematsu T, Ohryohji F, Nawata H, Ishibashi H, Maeda Y, Kiyokawa H, Tokunaga K, Irita Y, Takeshita S, Arase Y and Nishino N (1991) Hepatitis C and hepatitis B in the etiology of hepatocellular carcinoma in the Japanese population. Cancer Res 51: 2842-2847

The Liver Cancer Study Group of Japan (1994) Predictive factors for long term prognosis after partial hepatectomy for patients with hepatocellular carcinoma in Japan. Cancer 74: 2772-2780

Tokino T, Fukushige S, Nakamura T, Nagaya T, Murotsu T, Shiga K, Aoki N and Matsubara K (1987) Chromosomal translocation and inverted duplication associated with integrated hepatitis B virus DNA in hepatocellular carcinomas. J Virol 61: 3848-3854

Tsuda H, Zhang W, Shimosato Y, Yokota J, Terada M, Sugimura T, Miyamura T and Hirohashi S (1990) Allele loss on chromosome 16 associated with progression of human hepatocellular carcinoma. Proc Natl Acad Sci USA 87: 6791-6794

Van Rensburg SJ, Cook-Mozafarri P, Van Schlkwyk DJ, Van Der Watt JJ, Vincent TJ and Purchase IF (1985) Hepatocellular carcinoma and dietary aflatoxin in Mozambique and Transkei. Br J Cancer 51: 713-726

Wang J, Chenivesse X, Henglein B and Brechot C (1990) Hepatitis B virus integration in a cyclin A gene in a hepatocellular carcinoma. Nature 343 : $555-557$

Whelan SL, Parkin DM and Masuyer E (eds) (1993) Trends in Cancer Incidence and Mortality. IARC Scientific Publ., No. 102. IARC: Lyon

Yeh SH, Chen PJ, Chen HL, Lai MY, Wang CC and Chen DS (1994) Frequent genetic alterations at the diastal region of chromosome $1 \mathrm{p}$ in human hepatocellular carcinomas. Cancer Res 54: 4188-4192

Yeh SH, Chen PJ, Lai MY and Chen DS (1996) Allelic loss on chromosome 4q and $16 \mathrm{q}$ in hepatocellular carcinoma: association with elevated $\alpha$-fetoprotein production. Gastroenterology 110: 184-192

Zhang W, Hirohashi S, Tsuda H, Shimosato Y, Yokota J, Terada M and Sugimura T (1990) Frequent loss of heterozygosity of chromosomes 16 and 4 in human hepatocellular carcinoma. Jpn J Cancer Res 81: 108-111 